\title{
Perancangan Filter Penjernih Air Sungai Kahayan Berbasis Pasir Silika Dan Lempung Alam Asal Kalimantan Tengah
}

\section{Design of Kahayan River Water Treatment Filter Based Silica Sand and Natural Clay of Central Kalimantan}

\author{
Revianti Coenraad $^{1 *}$, Wiratno ${ }^{2}$, Karelius $^{3}$ \\ ${ }^{1}$ Prodi Pendidikan Teknik Bangunan Universitas Palangka Raya, Kampus UPR J1. H. Timang, Palangka Raya \\ ${ }^{2}$ Prodi Pendidikan Teknik Bangunan Universitas Palangka Raya, Kampus UPR Jl. H. Timang, Palangka Raya \\ ${ }^{3}$ Prodi Kimia FMIPA Universitas Palangka Raya, Kampus UPR Jl. H. Timang, Palangka Raya
}

*Alamat email: revianti@ptb.upr.ac.id

\begin{abstract}
Abstrak - Salah satu cara pengolahan air yang sederhana dan ramah lingkungan adalah melalui proses penyaringan dengan instalasi penyaringan air sederhana (IPAS) menggunakan bahan alam. Bahan alam yang dapat digunakan sebagai filter dalam instalasi penjernihan air sederhana adalah pasir silika dan lempung alam yang diaktivasi. Pengambilan sampel sungai akan dilakukan di DAS (Daerah Aliran Sungai) Kahayan Kalimantan Tengah. Sampling air akan dilakukan pada saat musim kemarau sehingga tidak ada pengaruh pengenceran. Filter pasir silika dan kerikil diperoleh dari toko penjual ikan hias yaitu pasir ukuran halus dan kasar. Filter lempung mangan dapat dibuat dengan menggunakan lempung alam yang perlakukan dengan $\mathrm{MnCl}_{2}$ dan $\mathrm{KMnO}_{4}$. Hasil pengujian menunjukkan filter lempung mangan dan arang aktif mampu menyaring zat-zat berbahaya yang terlarut dalam air, menghilangkan bau dan menjernihkan air sungai kahayan yang keruh. Air sungai kahayan yang sebelum dilakukan penjernihan memiliki nilai pH 5,5, kandungan Fe 2,16 mg/L, total padatan tersuspensi (TSS) $258 \mathrm{mg} / \mathrm{L}$, total padatan terlarut $30 \mathrm{mg} / \mathrm{L}$, kekeruhan 140 NTU dan sangat bau. Setelah dilakukan penjernihan dengan instalasi penjernihan air, penjernihan memiliki nilai pH 6,5, kandungan Fe 0,7 mg/L, total padatan tersuspensi (TSS) $134 \mathrm{mg} / \mathrm{L}$, total padatan terlarut $32 \mathrm{mg} / \mathrm{L}$, kekeruhan 35,3 NTU dan tidak berbau. Hasil penjernihan air ini cukup layak digunanakan sebagai air bersih karena nilai pH, kandungan Fe, TDS, TSS, kekeruhan dan bau sesuai dengan syarat air bersih menurut Permenkes RI No: 416/MENKES/PER/IX/1990.
\end{abstract}

Kata Kunci: arang aktif, lempung, sungai kahayan

\begin{abstract}
One of the simple water treatments and sustainably green for the environment is through the filter system, namely Instalasi Penyaringan Air Sederhana (IPAS), using sustainable and natural materials. Those materials are such as silica sand and activated natural clay. The extraction of freshwater samples is taken from the Kahayan watershed (DAS) in Central Kalimantan. Taking a sample is during the dry season thus there is no diluted effect. Silica and gravel sand filters are obtained from ornamental fish sellers, which are fine and coarse-sized sand. The manganic clay filter can be synthesized by using the natural clay that treated as $\mathrm{MnCl}_{2}$ and $\mathrm{KMnO}_{4}$. According to the laboratory test result, the manganic clay filter and active activated carbon have the capability to filter and absorb the harmful substances which are contained in freshwater, to neutralize the unpleasant smell, and to purify the turbid water from Kayahan river. The previous properties of freshwater of Kahayan river have $\mathrm{pH} 5.5$, metal particles Fe at value $2.16 \mathrm{mg} / \mathrm{L}$, total suspended solidity (TTS) at value $258 \mathrm{mg} / \mathrm{L}$, turbidity level at $140 \mathrm{NTU}$, and unpleasant odor. After the purification is done by freshwater installation filter, the purified water as the filtering result has the properties respectively about acid level (pH) 6.5, metal Fe substance at $0.7 \mathrm{mg} / \mathrm{L}$, total suspended solidity (TTS) $134 \mathrm{mg} / \mathrm{L}$, total soluble solidity at $32 \mathrm{mg} / \mathrm{L}$, turbidity level at $35.3 \mathrm{NTU}$, and scenes. This result of freshwater filtering is being satisfied and healthy to be consumed as daily water for domestic people due to possessing the value of acid level ( $p H)$, metal Fe substance, TDS, TSS, turbidity level, and smell are acceptable to the criterion of healthy water standard according to Regulation of Indonesian Health Ministry (Permenkes RI) No: 416/MENKES/PER/IX/1990.
\end{abstract}

Keywords: activated carbon, clay, kahayan river

() 2019 Jurnal Jejaring Matematika dan Sains. This work is licensed under a CC BY-NC 4.0

Sejarah Artikel

Diterima : 16 November 2019

Disetujui : 24 Desember 2019 


\section{PENDAHULUAN}

Air yang dibutuhkan oleh manusia untuk hidup sehat harus memenuhi syarat kualitas dan kuantitas (jumlahnya). Dari aspek kualitas, air bersih yang layak untuk digunakan harus memenuhi syarat fisik, kimia dan juga mikrobiologi. Syarat fisik, antara lain : air harus bersih dan tidak keruh, tidak berwarna, tidak berasa, tidak berbau, suhu tidak berbeda lebih dari $3{ }^{\circ} \mathrm{C}$ dari suhu udara dan tidak meninggalkan endapan. Syarat fisik tidak berbau, tidak berasa dan jernih. Sementara syarat kimiawi, antara lain: tidak mengandung zat-zat kimiawi yang berlebihan, cukup yodium, $\mathrm{pH}$ air antara 6,5-8,5. Syarat mikrobiologi, antara lain: tidak mengandung kuman-kuman penyakit seperti disentri, tipus, kolera, dan bakteri patogen penyebab penyakit [1].

Salah satu sumber air di Kalimantan Tengah adalah Sungai Kahayan. Sungai Kahayan merupakan salah satu sungai besar di Kalimantan Tengah yang memiliki panjang lebih kurang $600 \mathrm{Km}$. Sungai ini melalui 2 kabupaten yaitu kabupaten Gunung Mas dan Pulang Pisau serta 1 kota yaitu kota Palangka Raya. Namun, kini kondisi air sungai Kahayan menjadi sangat menghawatirkan. Air sungai Kahayan kini menjadi sangat keruh, mengandung kadar besi tinggi dan asam. Menurut Kepala Badan Lingkungan Hidup Pemerintah Kota Palangkaraya, Rawang, mengatakan, bahwa kekeruhan air di Sungai Kahayan disebabkan karena berbagai aktivitas masyarakat di sepanjang pinggiran sungai Kahayan. Air yang pada hakekatnya tidak memenuhi standar air bersih perlu dilakukan proses pengolahan sehingga komponen yang tidak diinginan di dalamnya dapat dihilangkan atau dikurangi. Pengolahan air tersebut salah satunya dengan proses penjernihan. Proses penjernihan merupakan proses perubahan sifat fisik, kimia dan biologi air baku agar memenuhi syarat untuk digunakan sebagai air bersih [2].

Selama ini masyarakat di daerah pinggiran Sungai Kahayan memanfaatkan tawas untuk penjernihan air Kahayan menjadi air bersih. Tawas atau Aluminium sulfat digunakan karena harganya yang relatif murah dan mudah diperoleh. Namun, penggunaan tawas yang berlebihan dapat berbahaya bagi kesehatan karena Aluminum yang terdapat dalam tawas dalam kosentrasi yang tinggi dalam air minum dapat menimbulkan problem seperti indikasi penyakit gagal ginjal dan Alzheimer [2].

Salah satu cara pengolahan air yang sederhana dan ramah lingkungan adalah melalui proses penyaringan (filtrasi) menggunakan bahan alam yang dimodifikasi [36]. Hasil penelitian sebelumnya menunjukan bahan alam seperti pasir, ziolit, kerikil dan bahan alam lainnya dapat digunakan sebagai filter dalam penjernihan air [7]. Zeolit dalam penelitian Said (2009) dimodifikasi dengan memasukkan Mangan ke dalam zeolit sehingga menghasilkan mangan-zeolit yang sangat efektif untuk menurunkan kadar besi $(\mathrm{Fe})$ yang terlarut dalam air serta menaikkan $\mathrm{pH}$ dan mengurangi kekeruhan. Penelitian lain oleh Purwoto (2016) menyebutkan bahwa treatment ferrolite, manganese zeolite, dan ion exchanger berupa resin anion dan resin kation pada air tanah mampu meremoval kandungan beban kekeruhan, warna, dan logam logam Besi, Kromium, serta Mangan hingga menjadi kriteria parameter air bersih [8].

Selain zeolit ternyata lempung dapat digunakan untuk menjernihkan air. Berdasarkan penelitian Lemley et al (2005) dan Rachmah (2014) lempung aktif sangat efektif untuk mengurangi senyawa organik, klorin, timbal, bau dan rasa yang tidak diinginkan dalam air. lempung aktif memiliki daya adsoripsi yang tinggi sehingga dapat mengadsorbsi zat-zat pengotor dalam air [9-10]. Lempung alam memiliki struktur kerangka yang mirip dengan zeolit, yaitu struktur kerangka silikaalumina, sehingga dapat digunakan sebagai bahan pengganti untuk zeolit. Penelitian lain yang dilakukan oleh Trimaily et al (2017) menyebutkan bahwa lempung terbuti efektif untuk mengolah air gambut menjadi air bersih [11]. Lempung memiliki karakteristik ruang antar lapis, gugus silanol dan aluminol yang memungkinkan lempung dapat berfungsi sebagai membrane support untuk produksi membran, yang sebagai salah satu bahan filter untuk menghasilkan air bersih [12].

Lempung telah diketahui dapat berfungsi sebagai koagulan dan adsorben logam-logam berat dan zat warna dalam air [13-14]. Kalimantan sangat kaya akan lempung alam, tetapi lempung alam umumnya masih bermutu rendah karena material lempung masih tercampur dengan mineral lain. Agar lempung alam memiliki nilai ekonomis tinggi, lempung perlu dimurnikan dan diolah serta dimodifikasi dengan $\mathrm{KMnO}_{4}$ dan $\mathrm{MnCl}_{2}$ untuk meningkatkan daya serap dan pertukaran ion [5]. Lempung alam asal Kalimantan Tengah yang telah dimodifikasi akan menghasilkan lempung-mangan sebagai salah satu bahan filter air sungai Kahayan untuk sumber air bersih alternatif di Kalimantan Tengah.

\section{BAHAN DAN METODE}

\section{A. Persiapan Sampel}

Pengambilan sampel sungai akan dilakukan di DAS (Daerah Aliran Sungai) Kahayan Kalimantan Tengah, sedangkan penelitian dilaksanakan di Laboratorium Pendidikan Kimia FKIP dan Laboratorium Dasar dan Analitik Universitas Palangka Raya. Alat-alat yang digunakan dalam penelitian ini adalah; Perangkat Alat gelas, Air Concept, tanur, AAS, Neraca Analitik, desikator, $\mathrm{pH}$ Meter, Turbidity meter. Bahan-bahan yang digunakan dalam penelitian ini adalah kasa berbahan logam, larutan $\mathrm{HCl} 0,5 \mathrm{M}$, larutan $\mathrm{MnCl}_{2} 5 \mathrm{~g} / \mathrm{L}$, larutan $\mathrm{KMnO}_{4} 5 \mathrm{~g} / \mathrm{L}$, larutan $\mathrm{AgNO}_{3}$ 0,1 M, pH universal, 
kerikil, pasir kasar, pasir halus, lempung, air sungai Kahayan, alumunium foil.

Sampling air sungai akan dilakukan di daerah sekitar DAS (Daerah Aliran Sungai) Kahayan. Sampling air akan dilakukan pada saat musim kemarau sehingga tidak ada pengaruh pengenceran. Penentuan titik sampling air sungai akan ditentukan secara Judgement random sampling pada sepanjang aliran sungai Kahayan, dengan titik sampling sebanyak 3 titik, sampling dilakukan dengan menggunakan peralatan sampling air. Hasil sampling yang diambil diakumulasikan menjadi satu (composite sampling), sehingga akan diperoleh 1 (satu) sample air sungai dari 3 (tiga) lokasi yang berbeda. Sempel yang diperoleh ditempatkan pada wadah yang telah disiapkan dan ditambahkan beberapa tetes asam encer $\left(\mathrm{HNO}_{3} 0,01 \mathrm{M}\right)$ untuk pengawetan sempel sampai siap di analisis di laboratorium.

Instalasi penjernihan air ini dirancang menggunakan beberapa filter pembantu selain lempung mangan yaitu kerikil, pasir kasar, pasir halus. Kerikil, pasir kasar dan pasir halus dicuci sampai bersih untuk menghilangkan partikel-partikel pengotor. Jika sudah bersih dilakukan pengeringan di bawah sinar matahari selama 1 hari.

\section{B. Sintesis Lempung Mangan}

Lempung dibasahi dan dibentuk dengan ukuran diameter $1 \mathrm{~cm}$, kemudian di tanur dengan suhu $700^{\circ} \mathrm{C}$ selama 3 jam. Lempung yang sudah kering kemudian direndam dengan menggunakan larutan $\mathrm{MnCl}_{2} 5 \mathrm{~g} / \mathrm{L}$ sambil di oven dengan air concept dengan suhu $60^{\circ} \mathrm{C}$ selama 12 jam. Setelah direndam selama 12 jam, lempung kemudian dicuci sampai bersih (tidak mengandung ion $\mathrm{Cl}^{-}$). Pada setiap pengulangan pencucian, filtrat diuji dengan larutan $\mathrm{AgNO}_{3} 0,1 \mathrm{M}$. Pencucian dilakukan sampai fitrat tidak memberikan endapan berwarna putih ketika ditetes $\mathrm{AgNO}_{3}$. Setelah lempung bersih (bebas ion $\mathrm{Cl}^{-}$) lempung kemudian di keringkan dengan air concept dengan suhu $80^{\circ} \mathrm{C}$ selama 3 jam. Kemudian, lempung direndam dengan larutan $\mathrm{KmnO}_{4}$ dengan kosentrasi $5 \mathrm{~g} / \mathrm{L}$ lalu di oven dengan air concept dengan suhu $60^{\circ} \mathrm{C}$ selama 24 jam. Setelah direndam selama 24 jam, lempung kemudian dicuci sampai bersih (filtrat cucian tidak berwarna unggu lagi). Filtrat cucian diuji dengan larutan $\mathrm{AgNO}_{3} \quad 0,1 \mathrm{M}$. Pencucian dilakukan sampai fitrat tidak memberikan endapan berwarna putih ketika ditetes $\mathrm{AgNO}_{3}$.Setelah lempung bersih, lempung kemudian di keringkan dengan air concept dengan suhu $80^{\circ} \mathrm{C}$ selama 3 jam.

\section{Perancangan Instalasi Penyaringan Air}

Instalasi penyaringan air dibuat dengan menggunakan galon berkeran. Design instalasi seperti Gambar 1 dengan proses penyaringan sebagai berikut :

1. Sample air sungai Kahayan dialirkan melalui filter pasir. Filtrat yang diperoleh kemudian ditampung untuk dianalisis pH, TSS, kekeruhan, kadar Fe

2. Filtrat dari hasil filter pasir kemudian dialirkan ke filter lempung mangan. Filtrat yang diperoleh kemudian ditampung untuk dianalisis $\mathrm{pH}$, TSS, kekeruhan, kadar Fe.

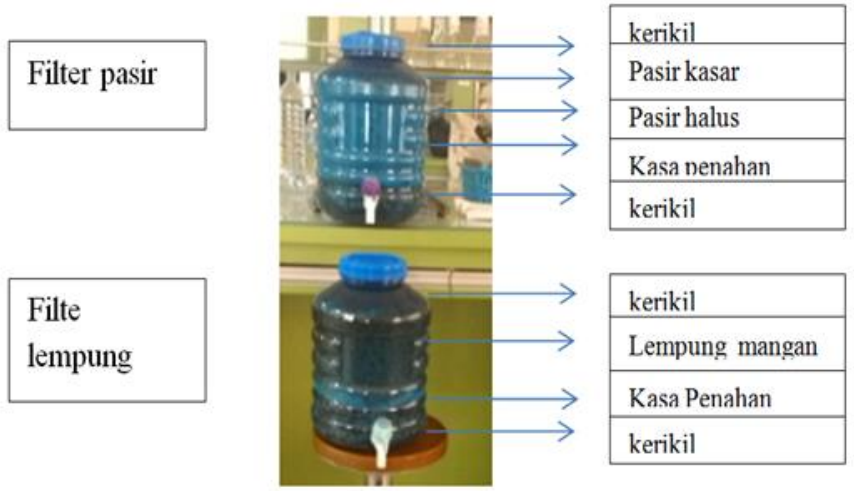

Gambar 1. Instalasi Penyaringan Air

\section{Analisis Sampel Air Sungai Kahayan}

Sampel air sungai Kahayan yang telah dijernihkan kemudian dianalisis di Laboratorium Analitik, Laboratorium Perikanan dan Laboratorium Kimia Universitas Palangkaraya untuk dilakukan pengujian $\mathrm{pH}$, TSS (Total Suspended Solid), kekeruhan (NTU), kadar besi (Fe). Pengujian terhadap parameter kualitas air tersebut dilakukan untuk air sungai Kahayan (umpan), air hasil filtrasi pasir dan air hasil filtrasi lempung mangan.

\section{HASIL DAN PEMBAHASAN}

\section{A. Sintesis Lempung Mangan}

Lempung yang telah dipreparasi di tanur dengan suhu $700^{\circ} \mathrm{C}$ selama 3 jam tujuannya agar molekul air yang terikat baik di dalam dan di luar kerangka lempung menguap. Harapannya dengan menguapnya molekul air dapat memperbesar ukuran lempung. Lempung yang sudah kering kemudian direndam dengan menggunakan larutan $\mathrm{MnCl}_{2} 5 \mathrm{~g} / \mathrm{L}$. Lempung kemudian dicuci sampai bersih (tidak mengandung ion $\mathrm{Cl}^{-}$). Setiap pengulangan pencucian, filtrat diuji dengan larutan $\mathrm{AgNO}_{3}$ 0,1 M. Pencucian dilakukan sampai fitrat tidak memberikan endapan berwarna putih ketika ditetes $\mathrm{AgNO}_{3}$. Setelah lempung bersih (bebas ion $\mathrm{Cl}^{-}$) lempung kemudian di keringkan dengan air concept dengan suhu $80^{\circ} \mathrm{C}$ selama 3 jam. Kemudian, lempung direndam dengan larutan $\mathrm{KMnO}_{4}$ dengan kosentrasi $5 \mathrm{~g} / \mathrm{L}$ lalu di oven dengan air concept dengan suhu $60^{\circ} \mathrm{C}$ selama 24 jam. Setelah direndam selama 24 jam, lempung kemudian dicuci sampai bersih (filtrat cucian tidak berwarna unggu lagi). Filtrat cucian diuji dengan larutan $\mathrm{AgNO}_{3}$ 0,1 $\mathrm{M}$. Pencucian dilakukan sampai fitrat tidak memberikan endapan berwarna putih ketika ditetes $\mathrm{AgNO}_{3}$. Setelah lempung bersih, lempung kemudian di keringkan dengan air concept dengan suhu $80^{\circ} \mathrm{C}$ selama 3 jam. Reaksi pengujian keberadaan ion $\mathrm{Cl}^{-}$adalah sebagai berikut :

$\mathrm{HCl}_{(\mathrm{aq})}+\mathrm{AgNO}_{3}(\mathrm{aq}) \rightarrow \mathrm{AgCl}_{(\mathrm{s})}+\mathrm{HNO}_{(\mathrm{aq})}$

Lempung yang diperlakukan dengan $\mathrm{MnCl}_{2}$ dan $\mathrm{KMnO}_{4}$ akan menjadi lempung mangan yang terdapat 
tiga komponen $\mathrm{Mn}$ yaitu $\mathrm{Mn}-\mathrm{L}\left(\mathrm{Mn}^{2+}\right.$ berada dalam sangkar lempung silika tetrahedron dan aluminium oktahedron, K-L (hasil pertukaran ion $\mathrm{K}^{+}$dari $\mathrm{KMnO}_{4}$ dengan Mn-L) dan oksida mangan dalam bentuk hasil reaksi oksidasi $\mathrm{MnO}_{4}^{-}$menjadi $\mathrm{MnO}_{2}$ dalam suasana netral. Pada reaksi tersebut terbentuk $\mathrm{Mn}^{2+}$ yang kemudian akan diikat kembali kedalam sangkar lempung (tetrahedron dan aluminium oktahedron)

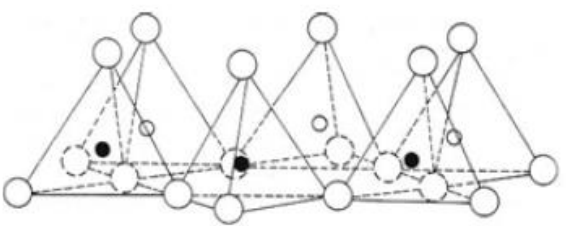

Gambar 2. Sangkar Lempung Tetrahedron silikon

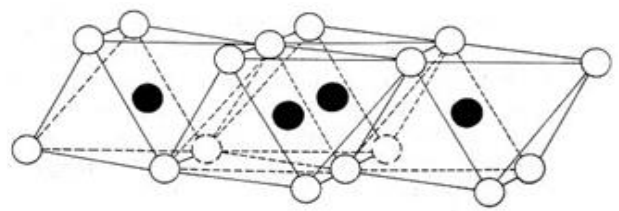

Gambar 3. Sangkar Lempung Oktahedron Aluminium

\section{B. Proses Penyaringan Menggunakan Filter Pasir dan Filter Lempung Mangan}

Instalasi penjernihan air ini dirancang menggunakan beberapa filter pembantu selain lempung mangan yaitu kerikil, pasir kasar, pasir halus. Kerikil, pasir kasar dan pasir halus dicuci sampai bersih untuk menghilangkan partikel-partikel pengotor. Jika sudah bersih dilakukan pengeringan di bawah sinar matahari selama 1 hari. Setelah semua filter siap dilakukan proses penyaringan air dengan cara :

1. Sample air sungai Kahayan dialirkan melalui filter pasir. Filtrat yang diperoleh kemudian ditampung untuk dianalisis $\mathrm{pH}$, TSS, kekeruhan, kadar Fe

2. Filtrat dari hasil filter pasir kemudian dialirkan ke filter lempung mangan. Filtrat yang diperoleh kemudian ditampung untuk dianalisis $\mathrm{pH}$, TSS, kekeruhan, kadar Fe.

Proses penyaringan dengan menggunakan filter pasir bukan merupakan proses utama pengolahan air sungai Kahayan. Filter pasir hanya merupakan filter pembantu untuk menyaring kotoran-kotoran berukuran besar pada air sungai Kahayan sebelum disaring dengan menggunakan filter lempung mangan. Tujuannya digunakan filter pembantu adalah mengoptimalkan kerja filter lempung mangan dalam proses pengolahan air sungai Kahayan sebagai sumber air bersih alternatif di Kalimantan Tengah.
C. Pengujian pH Air Sungai Kahayan

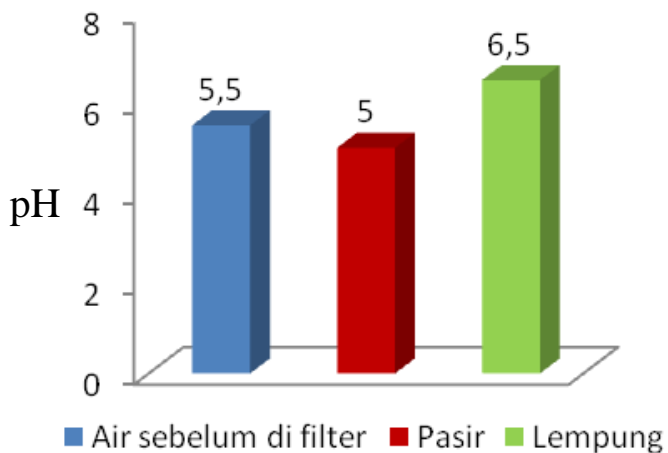

Gambar 4. Hasil pengujian $\mathrm{pH}$

Hasil Pengujian $\mathrm{pH}$ menunjukkan terjadi kenaikan pH air yaitu dari 5,5 menjadi 6,5. Kenaikan pH ini dikarenakan pada saat proses pemfilteran, air yang mengalir melalui media filter mengalami tumbukan atau benturan antar molekul air yang mengakibatkan terjadinya gelembung-gelembung udara (air melepaskan oksigen) sehingga terjadi reaksi ion yang mengakibatkan air kelebihan ion $\mathrm{H}^{+}$, sehingga $\mathrm{pH}$ air meningkat. Selain itu keberadaan gugus silanol dan aluminol dalam lempung memiliki afinitas besar terhadap ion $\mathrm{H}^{+}$dalam air, sehingga ion $\mathrm{H}^{+}$dalam air sebagai sumber asam akan banyak berikatan dengan gugus silanol dan aluminol dalam lempung, mengakibatkan menurunnya konsentrasi ion $\mathrm{H}^{+}$dalam air yang menyebabkan meningkatnya nilai $\mathrm{pH}$.

Sebagai hasil filtrasi, $\mathrm{pH}$ air sungai Kahayan yang awalnya asam yaitu 5, setelah melalui filter lempung mangan air sungai Kahayan memiliki pH 6,5. Nilai pH ini memenuhi syarat air bersih yang ditetapkan oleh kementrian kesehatan republik indonesia dalam Permenkes RI No. 907/MENKES/VII/2002 yaitu pH 6,5 - 9. Jadi berdasarkan nilai $\mathrm{pH}$ lempung mangan ini berhasil menaikan $\mathrm{pH}$ air sungai Kahayan sebagai sumber air bersih alternatif.

\section{Pengujian Kadar Besi (Fe)}

Besi adalah salah satu elemen yang dapat ditemukan hampir setiap tempat di bumi, pada semua lapisan geologis dan semua badan air (sungai). Besi jarang ditemui pada permukaan air dengan kadar kadar Fe lebih besar dari $1 \mathrm{mg} / \mathrm{L}$, akan tetapi di dalam air tanah Fe jauh lebih tinggi. Air yang tidak mengandung $\mathrm{O}_{2}$, besi berada sebagai $\mathrm{Fe}^{2+}$ yang dapat terlarut, sedangkan pada air sungai yang mengalir menyebabkan $\mathrm{Fe}^{2+}$ teroksidasi menjadi $\mathrm{Fe}^{3+}$. Besi dalam air sungai berada sebagai $\mathrm{Fe}^{2+}$, $\mathrm{Fe}^{3+}$ terlarut dan $\mathrm{Fe}^{3+}$ dalam bentuk senyawa organik berupa kolodial, sehingga kadarnya dapat diturunkan dengan melewatkannya pada lempung mangan. Berikut hasil analisa kadar besi dalam air sungai Kahayan, sebelum dan sesudah perlakuan : 


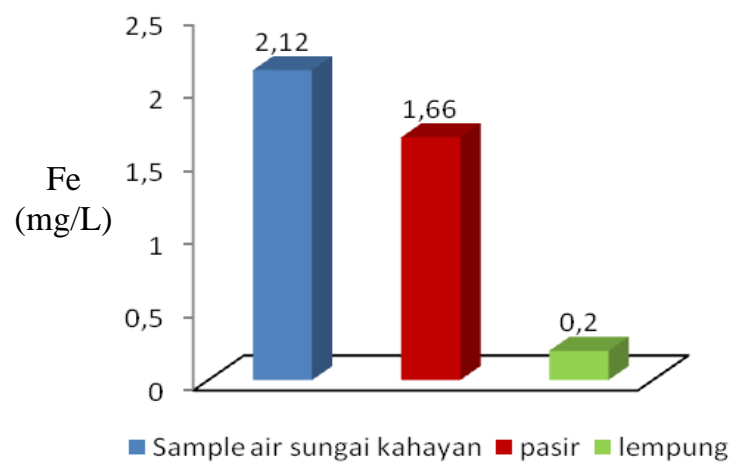

Gambar 5. Hasil Pengujian Kadar Fe

Penurunan kadar besi terlihat pada Gambar 5. Kadar awal besi pada air sungai Kahayan adalah $2,12 \mathrm{mg} / \mathrm{L}$ turun menjadi $1,66 \mathrm{mg} / \mathrm{L}$ setelah melewati filter pasir, dan kadar besi terendah yaitu setelah melalui filter lempung mangan dengan kadar besi 0,2 mg/L. Penurunan kadar besi sebagai ion $\mathrm{Fe}^{3+}$ pada air yang telah difilter disebabkan karena ion $\mathrm{Fe}^{3+}$ direduksi oleh lempung mangan. Terdapat tiga Lempung mangan yaitu $\mathrm{Mn}-\mathrm{L} \quad \mathrm{Mn}^{2+}$ berada dalam sangkar lempung silika tetrahedron dan aluminium oktahedron, K-L (hasil pertukaran ion $\mathrm{K}^{+}$dari $\mathrm{KMnO}_{4}$ dengan $\mathrm{Mn}-\mathrm{L}$ ) dan oksida mangan dalam bentuk hasil reaksi oksidasi $\mathrm{MnO}_{4}^{-}$ menjadi $\mathrm{MnO}_{2}$ dalam suasana netral. Ketiga macam senyawa Mn juga bersifat adsorben sehingga penyerapan $\mathrm{Fe}^{3+}$ lebih efisien.

Lempung MnO-L dapat berfungsi sebagai katalis dan pada waktu yang bersamaan dapat mengoksidasi besi yang larut dalam air sungai Kahayan menjadi tidak larut dalam air dan menempel pada permukaan MnO-L yang juga berperan sebagai adsorben. Reaksi yang terjadi antara Fe dengan ketiga spesi lempung mangan tersebut adalah sebagai berikut:

$$
\begin{aligned}
& \mathrm{Mn}-\mathrm{L}+\mathrm{Fe}^{3+} \rightarrow \mathrm{Fe}-\mathrm{L}+\mathrm{Mn}^{2+} \\
& \mathrm{K}-\mathrm{L}+\mathrm{Fe}^{3+} \rightarrow \mathrm{Fe}-\mathrm{L}+\mathrm{K}^{+} \\
& \mathrm{MnO}-\mathrm{L}+\mathrm{Fe}^{3+} \rightarrow \mathrm{Fe}-\mathrm{L}+\mathrm{Fe}(\mathrm{OH})_{3}+\mathrm{Mn}^{2+}
\end{aligned}
$$

Reaksi tersebut menunjukkan setelah terbentuk $\mathrm{Mn}^{2+}$, maka kemudian $\mathrm{Mn}^{2+}$ akan diikat kembali kedalam sangkar lempung (tetrahedron dan aluminium oktahedron) dan besi sebagai $\mathrm{Fe}(\mathrm{OH})_{3}$ akan diadsorbsi oleh permukaan $\mathrm{MnO}-\mathrm{L}$ [8].

Hasil analisa kadar $\mathrm{Fe}$ setelah di lakukan penyaringan dengan filter lempung mangan adalah 0,2 mg/L. Jika dibandingkan dengan kadar Fe syarat air bersih menurut Permenkes RI No. 907/MENKES/VII/2002 yaitu $1 \mathrm{mg} / \mathrm{L}$. Kadar Fe dalam air sungai Kahayan hasil penyaringan dengan filter lempung mangan berada di bawah kadar yang disyaratkan untuk air bersih. Sehingga dapat dikatakan untuk parameter kualitas air kadar Fe, maka air sungai Kahayan hasil penyaringan dengan filter lempung mangan layak digunakan sebagai sumber air bersih alternatif.

\section{E. Pengujian TSS (Total Suspended Solid)}

Selain nilai $\mathrm{pH}$ dan kadar Fe, juga diuji nilai TSS pada air sungai Kahayan baik sebelum dan Sesudah pernyaringan menggunkan filter pasir dan filter lempung mangan. Hasil pengujian terhadap nilai TSS dapat dilihat pada Gambar 6.

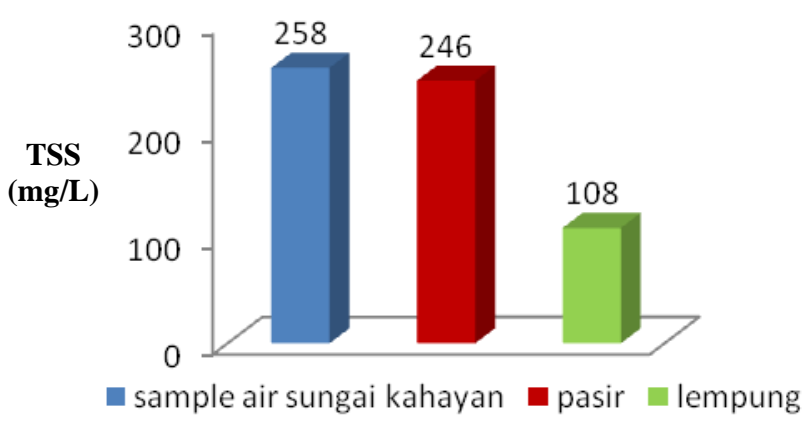

Gambar 6. Hasil Pengujian Nilai TSS

Gambar 6, memperlihatkan bahwa nilai TSS air sungai Kahayan hasil filter lempung mangan lebih rendah dari filter lainnya. Nilai TSS air sungai Kahayan sebelum di filter adalah $258 \mathrm{mg} / \mathrm{L}$, setelah di filter dengan pasir nilai TSS air sungai Kahayan menurun menjadi 246 $\mathrm{mg} / \mathrm{L}$. Pada filter lempung mangan nilai TSS air sungai Kahayan menurun drastis menjadi 108 mg/L. Keberadaan muatan pada situs aktif lempung membuat lempung memiliki kemapuan adsorpsi yang tinggi. Dua prinsip dari mekanisme adsorpsi adalah adsorpsi fisik dan adsorpsi kimia. Adsorpsi fisik akan terjadi bila terdapat perbedaan energi dan atau gaya tarik sehingga molekul adsorbat terikat secara fisik pada molekul adsorben. Sedangkan jika molekul-molekul zat menempel pada permukaan adsorban melalui reaksi kimia dan pembentukan ikatan kimia, fenomena ini disebut sebagai adsorpsi kimia. Proses adsorpsi kimia merupakan proses yang bersifat irrevesible yang memerlukan energi untuk membentuk senyawa kimia yang baru pada permukaan adsorben.

Lempung mangan pada proses ini dapat bertindak sebagai koagulan yang mengikat padatan-padatan tersuspensi dalam air, sehingga akhirnya membentuk flok yang tertahan pada permukaan adsorben. Pengikatan yang terjadi tidak melibatkan pembentukan ikatan kimia dan membentuk senyawa baru pada permukaan adsorben, melainkan hanya interaksi fisik akibat berdapatnya muatan pada situs aktif lempung yaitu silanol dan aluminol dengan molekul adsorbat yang terdapat dalam air sungai Kahayan. Sehingga adsorpsi yang terjadi tergolong sebagai adsorpsi fisik.

Nilai TSS yang memenuhi syarat air bersih yang ditetapkan oleh kementrian kesehatan republik indonesia dalam Permenkes RI No. 907/MENKES/VII/2002 adalah di bawah $200 \mathrm{mg} / \mathrm{L}$. Hasil analisa terhadap nilai TSS 
pada air sungai Kahayan setelah melalui filter lempung mangan adalah $108 \mathrm{mg} / \mathrm{L}$, berada di bawah baku mutu TSS untuk air bersih. Sehingga dapat dikatakan untuk parameter kualitas air TSS, maka air sungai Kahayan hasil penyaringan dengan filter lempung mangan layak digunakan sebagai sumber air bersih alternatif.

\section{F. Pengujian Kekeruhan}

Kejernihan air ditentukan oleh warna air atau kekeruhan (turbidity) dalam air. Di alam kekeruhan ini timbul sebagai akibat adanya pengotoran baik oleh tanah liat, lumpur, bahan organik maupun partikel kecil tersuspensi lainnya. Berikut adalah hasil analisa nilai kekeruhan (NTU) pada air sungai Kahayan sebelum dan sesudah perlakuan :

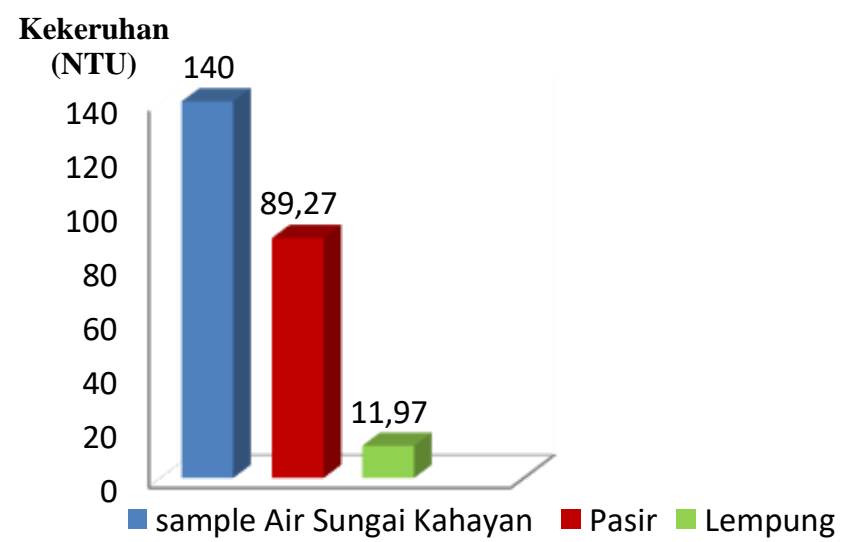

Gambar 7. Hasil Pengujian Kekeruhan

Gambar 7 memperlihatkan bahwa nilai kekeruhan air Kahayan sebelum dilakukan penyaringan adalah 140 NTU. Angka tersebut menunjukkan bahwa air sungai Kahayan tergolong keruh keruh. Penuruhan nilai kekeruhan air sungai Kahayan terlihat setelah penyaringan baik dengan filter pasir dan filter lempung mangan, yaitu masing-masing 89,27 NTU dan 11,97 NTU. Penurunan kekeruhan pada air sungai Kahayan dengan menggunakan filter pasir disebabkan filter pasir disusun sedemikian rupa dari partikel pasir besar kemudian pasir halus, sehingga pengotor baik berupa tanah liat, lumpur, bahan organik maupun partikel kecil tersuspensi lainnya dapatb tersaring oleh filter pasir [5]. Ternyata masih banyak pengotor halus yang lolos dari filter pasir yang menyebabkan nilai kekeruhan pada air sungai Kahayan hasil filter pasir masih tinggi yaitu 89,27 NTU.

Filtrat dari filter pasir kemudian dialirkan ke filter lempung mangan. Hasil penyaringan menunjukkan bahwa filter lempung mangan mampu menurunkan nilai kekeruhan sampai 11,27 NTU. Hal ini disebabkan karena lempung mangan memiliki kemampuan adsorpsi terhadap zat-zat terlarut dalam air sehingga dapat menurunkan kekeruhan air. Kemampuan adsorpsi tersebut tidak hanya melibatkan muatan pada situs aktif lempung tetapi juga keberadaan pori-pori lempung yang dapat menyerap partikel-partikel berukuran kecil yang masih terdapat pada filtrat hasil penyaringan dengan filter pasir sehingga mampu menurunkan kekeruhan secara signifikan [6].
Persyaratan air bersih yang ditetapkan oleh kementrian kesehatan republik indonesia dalam Permenkes RI No. 907/MENKES/VII/2002 untuk parameter kekeruhan adalah 25 NTU. Hasil analisa terhadap nilai kekeruhan pada air sungai Kahayan setelah melalui filter lempung mangan adalah 11,97 NTU, berada di bawah baku mutu kekeruhan untuk air bersih. Sehingga dapat dikatakan untuk parameter kualitas air kekeruhan, maka air sungai Kahayan hasil penyaringan dengan filter lempung mangan layak digunakan sebagai sumber air bersih alternatif.

\section{KESIMPULAN}

Lempung mangan sebagai salah satu bahan filter air sungai Kahayan mampu memperbaiki parameter kualitas air sungai Kahayan yaitu pH, kadar Fe, TSS dan kekeruhan sehingga sesuai dengan syarat air bersih menurut Permenkes RI No. 907/MENKES/VII/2002 dengan nilai masing-masing parameter yaitu $\mathrm{pH}$ 6,5, kadar Fe 0,2 mg/L, TSS 108 mg/L dan kekeruhan 11,97 NTU.

\section{REFERENSI}

[1] Depkes RI, 2002. Permenkes RI No. 907/MENKES/VII/2002 Tentang Syarat-Syarat dan Pengawasan Kualitas Air Minum. Depkes RI: Jakarta

[2] Tribunnews, 2011. Tercemar, Sungai Kahayan Masih Aman.

http://kalteng.tribunnews.com/2011/09/15/tercemarsungai-Kahayan-masih-aman. Diakses tanggal 16 September 2015.

[3] Susanto, Diko., Toibah Umi Kalsum, Yanolanda Suzantri H., 2014. Alat Penyaringan Air Kotor Menjadi Air Bersih Menggunakan Mikrokontroller Atmega 32, Jurnal Media Infotama, Vol. 10 No. 2, September 2014.

[4] Syahputra, andi., Sugianto, Riad Syech. 2015. Rancang Bangun Alat Penjernih Air Yang Tercemar Logam Berat $\mathrm{Fe}, \mathrm{Cu}, \mathrm{Zn}$ Dalam Skala Laboratorium, Jurnal JOM FMIPA, Volume 2 No. 1 Februari 2015.

[5] Mugiantoro, Alwin., Istifari Husna Rekinagara, Corintia Dian Primaristi, Joko Soesilo. 2017. Penggunaan Bahan Alam Zeolit, Pasir Silika, Dan Arang Aktif Dengan Kombinasi Teknik Shower Dalam Filterisasi Fe, Mn, Dan Mg Pada Air Tanah Di Upn "Veteran" Yogyakarta, PROCEEDING, SEMINAR NASIONAL KEBUMIAN KE-10 PERAN PENELITIAN ILMU KEBUMIAN DALAM PEMBANGUNAN INFRASTRUKTUR DI INDONESIA 13 - 14 SEPTEMBER 2017.

[6] Muliawan, Arief., Finta Amalinda. 2018. Efektivitas Pemakaian Filter Berpori Dan Karbon Aktif Sebagai Media Filter Dalam Menurunkan Polutan Air Pdam, PROMOTIF: Jurnal Kesehatan Masyarakat, Volume 8, Nomor 1, Juni 2018.

[7] Said, N. I. Wahjono H.D. 2009. Pembuatan Filter untuk Menghilangkan Zat Besi dan Mangan dalam Air, Jurnal Kimia Molekul Vol 10, No. 1 
[8] Purwoto, Setyo., Joko Sutrisno. 2016. Pengolahan Air Tanah Berbasis Treatment Ferrolite, Manganese Zeolite, dan Ion Exchange, Jurnal Teknik WAKTU, Volume 14, Nomor 02, Juli 2016.

[9] Lemnley, Ann., Wagenet and Kneen, Barbera. 2005. Activated Clay Treatment Of Drinking Water. http://academia.edu.com diakses tanggal 10 September 2015.

[10] Rachmah, N., Purwoto, S. 2014. "Efektifitas Penurunan Mn dan Total Coliform Pada Air Sumur Gali Berbasis Zeolit." WAKTU, ISSN : 1412-1867, ed. Januari 2014 12(1): 1-7.

[11] Trimaily, Devita., Nofrizal, Esy Maryanti. 2017. Efektivitas Penggunaan Tawas dan Tanah Lempung pada Pengolahan Air Gambut Menjadi Air Bersih, Dinamika Lingkungan Indonesia, Januari 2017, Vol. 4, No. 1, p 3952.

[12] Elma, Muthia., Isna Syauqiah, Nor Aldina, Hesti Kesumadewi. 2016. Karakterisasi Tanah Lempung Gambut Kalimantan Selatan Sebagai Bahan Baku Pembuatan Membrane Support, Jurnal Teknoin, Vol. 22, No 6 Desember 2016 : 437-443.

[13] Sadiana, I Made., Abdul Hadjranul Fatah, Karelius. 2017. Synthesis of Natural Clay Magnetite Coposite as Adsorbent of Methylene Blue, Jurnal Sains dan Terapan Kimia, Vol.11, No.2, 2017, p90-102.

[14] Sadiana, I Made.,Karelius, Retno Agnestisia, Abdul Hadjranul Fatah. 2018. Studies on Synthesis, Characterization and Adsorption of Cationic Dyes From Aqueous Solutions Using Magnetic Composite Mateial from Natural Clay in Central Kalimantan, Jurnal Molekul, Vol.13, No.1, Mei 2018, p63-71.

[15] Musyaddah, Yenoe, 2012. Optimasi Pengolahan Air Sungai Martapura Menjadi Air Bersih Dengan Memanfaatkan Tanah Lempung Lokal Sebagai Koagulan. Jurnal Sains dan Terapan Vol 5, No. 1, Hal : 23-30. 